\title{
Learning to Learn Culture: The Experiences of Sojourners in Nunavut
}

\author{
Christine Wihak (University of Calgary)
}

\begin{abstract}
Cross-cultural proficiency is vital for educational professionals, whether working abroad or in multicultural Canadian cities. This study explores the process of learning culture identified through an analysis of the narratives of 10 women counsellors who lived and worked in educational settings in Inuit communities in Nunavut. Their learning strategies parallelled the process described in adult learning theory, suggesting the usefulness of such theory for guiding the development of professional education and training programs aimed at the development of multicultural competence. In turn, the theoretical perspective highlights the importance of direct cultural immersion rather than an academic approach to learning culture.
\end{abstract}

\section{Résumé}

La compétence trans-culturelle est indispensable pour les professionnels dans l'enseignement, qu'ils travaillent à l'étranger ou dans les cités multiculturelles au Canada. Cet article explore le processus de l'apprentissage de la culture suivant l'analyse des récits de dix conseillères qui vivaient et travaillaient dans les milieux d'éducation des communautés d'Inuits en Nunavut. Leurs stratégies d'étude étaient équivalentes aux processus décrits dans les théories sur l'éducation des adultes, suggérant ainsi l'utilité de telles théories comme guide dans le développement de la formation professionnelle et des programmes de formation ayant pour but le développement de la compétence multiculturelle. A son tour, la perspective théorique souligne l'importance de l'immersion culturelle directe plutôt que l'approche académique dans l'étude de la culture.

\section{Learning to Learn Culture}

Multicultural or intercultural competence (ability to work effectively in crosscultural contexts) has been increasingly recognized as an important quality for educational professionals in today's globalized world. In this context, the term "culture" is used as it is commonly conceived in cross-cultural psychology to represent the collective experiences of a recognizable group (Kim, 2005).

Whether working abroad on international education projects or in North America's increasingly multicultural, multiracial cities (Chang, 2004; Engelbert, 2004; McAllister \& Irvine, 2000), professionals need such cultural proficiency. In this paper, I report on the cultural learning process of Euro-Canadian women who had worked in educational settings as counsellors (Wihak, 2004; Wihak \& Merali, 2005) in the remote and troubled (Korhonen, 2002) Inuit communities of Nunavut.

46 Canadian and International Education Vol. 35 no. 1 - June 2006 


\section{Literature on Learning Culture}

Little is known about the process whereby professionals develop multicultural competence or how to cultivate this ability in professional education programs (Fuertes, Bartolomeo \& Nichols, 2001). According to Jacobsen (1996), the main focus of the multicultural education movement has been on the place of culture in education, rather than on how culture is learned. Much research on sojourning (to live and work with another culture for an extended period) has focussed on "culture shock" and the description of processes involved in adapting to a new culture (Schild-Jones, 1999). Bennett (1986) articulated an influential model of the development of intercultural proficiency experienced by sojourners (people who, which described stages of cognitive and affective change necessary for the transformation from ethnocentrism to ethnorelativism. Kim (1988) also described a spiralling process of transformation, positing that stress, followed by adaptation, leads to growth.

Taylor (1994a) drew attention to the importance of adult learning theory (Mezirow, 1978, 1981, 1991) for understanding the developmental sequences that Bennett (1986) and Kim (1988) had described. Taylor pointed out that both models implied that learning is occurring, but did not explain the learning process. He argued that Mezirow's adult learning theory applies in the intercultural context. Taylor's (1994b) study of 12 American cross-cultural sojourners, however, indicated that Mezirow's theory was not sufficient to account for learning an intercultural perspective because of that theory's focus on reflection. Taylor found that many of his participants did not appear to use reflection but rather described perspective changes occurring through learning new habitual patterns in an unfamiliar cultural context. Taylor identified three primary learning strategies used by his participants: observing the other culture, participating in the other culture, and making friends with a member of the host culture. Other narrative studies of sojourners (Osland, 1995; Schild-Jones, 1999) have identified similar processes and learning strategies to those Taylor had described. Beyond this, both Osland (1996) and Schild-Jones (1999) repeatedly referred to the paradoxical nature of the cross-cultural situation, and how that precipitates the learning process. Their use of "paradox" drew my attention to Jarvis' (1992) theory of adult learning to explain the findings from my own research with sojourners.

In my qualitative inquiry with Nunavut sojourners, theoretical constructs were "held lightly in the background" (J. Ellis, personal communication, November, 2002), rather than used to focus the research. Throughout their narratives, the participants depicted themselves as experiencing significant personal and professional growth during their sojourns. All this learning, however, took place in a cultural milieu saturated with social problems, under conditions of professional isolation, and in a harsh physical environment. What could explain the paradox that so much growth and learning occurred in such difficult circumstances? 
Jarvis' (1992) work, entitled Paradoxes of Learning, was derived from empirical research with learners but drew on the work of theorists such as Schon (1983) and Kolb (1984), as well as Mezirow (1978, 1981, 1991). According to Jarvis (p. 83), "Disjuncture makes learning possible.” Disjuncture represents a lack of harmony between the person's interest and/or knowledge and her/his sociocultural world. The best conditions for learning occur when harmony is disturbed and the resultant disjuncture makes unthinking action impossible. Involvement in a different cultural context, particularly one like Nunavut, creates opportunity for experiencing disjuncture.

Jarvis (1992) postulated that learning can occur through multiple, interacting routes, which include both nonreflective and reflective learning, while acknowledging that non-learning can also be the response to new situations or information. Jarvis considered nonreflective learning, which results in non-innovative reproduction of cultural knowledge, as the primary way that people learn their place in society. Such nonreflective learning, a task faced anew by anyone working in novel cross-cultural contexts, has several different forms. Preconscious learning takes place on the periphery of consciousness. Memorization is another form of nonreflective learning, in which words of wisdom are learned from authorities. Nonreflective skills learning involves imitation and repetitive practice. In contrast, reflective learning offers the opportunity for innovations in knowledge to occur (Jarvis, 1992). Reflective learning encompasses contemplation, reflective skills learning, and experimental learning. Contemplation, a common form of learning, involves thinking about an experience and reaching a conclusion about it. Reflective skills learning occurs when a professional learns not only how to perform a skill, but also the principles underlying it. Experimental learning refers to testing theory in practice.

The current study of sojourners illustrates the usefulness of Jarvis' theory, thus extending the application of adult learning theory to the cultivation of multicultural competence.

\section{Process of Inquiry}

Participants

The participants were selected through a process of purposeful sampling (Patton, 1990) from an existing professional network. Selection criteria were: (1) lived in Nunavut for a minimum of two years with professional employment that involved educational counselling work with Inuit; (2) were born and raised in Canada, of Euro-Canadian origin; (3) used English as their working language, (4) had returned to southern Canada a minimum of one year and a maximum of ten years before the interview.

Ten women meeting these criteria participated in the research; the fact that they are all women reflects female predominance in the counselling profession. Some participants wanted to have their own names used, while others chose to disguise their identities by using a pseudonym. For those 
participants, I also disguised biographical details in the narratives. Their backgrounds are briefly described below:

1.) Bev spent 19 years in Nunavut working as a school guidance counsellor before becoming Director of a community counselling agency. Before her sojourn, she worked as a counsellor for Inuit students living in Ottawa. Bev returned to southern Canada a year before this study.

2.) Danya is a doctoral level psychologist who lived in Nunavut for two years, employed as a counsellor at a community college. This was her first cross-cultural counselling experience. She had been back in southern Canada for seven years at the time of the study.

3.) Debbie had graduate level training in educational psychology and human resource management, plus previous experience working with Aboriginal bands in Alberta. She spent seven years in Nunavut involved in both direct counselling and counsellor training in a college social work program. She returned to southern Canada six years before this study.

4.) Deborah, a criminologist who had participated in numerous foreign aid programs, spent six years in Nunavut, counselling in college and community settings. She had been back in southern Canada for nine years at the time of this study.

5.) Fluff is a psychiatric social worker (MSW), with previous crosscultural experience working with Aboriginal bands in several provinces. She lived in Nunavut for four years to work as a Mental Health Specialist, which involved work with teachers, parents and schoolchildren. She returned to southern Canada 10 years before this study was conducted.

6.) Meeka, an experienced multicultural educator, spent 10 years in Nunavut, directing a Life Skills program for Inuit youth and a program for children with behaviour disorders in a community school. Meeka returned to southern Canada seven years before this study took place.

7.) Michelle, a social worker (BSW) with no previous cross-cultural experience, worked for four years in Nunavut as a Mental Health Specialist, which encompassed work with schoolchildren. She had been back in Southern Canada for a decade prior to this study.

8.) Patricia had worked with the Mi'qmaq people in Nova Scotia after completing an MSW. In Nunavut for four years, she co-ordinated a Community Wellness Program, which involved work in schools. She had returned to southern Canada one year before participating in this research.

9.) Rebecca, a social worker (BSW) with previous cross-cultural experience teaching English in South America, worked for two years in a community counsellor position that involved work with adult students at the local community college. She returned to southern Canada 2 years prior to the study. 
10.) Soshana had completed a master's in community psychology with cross-cultural course work. She also worked as a Mental Health Specialist in Nunavut for four years, including work with community schools. She had been back in southern Canada for nine years before the study.

Research Interviews

Acceptable ethical practices were followed throughout the interview process. Participants' narratives were collected through tape-recorded personal interviews. Each participant was asked to speak about her own experience of living and working in Nunavut, with theoretical constructs "held lightly in the background" (J. Ellis, personal communication, November, 2002) rather than used to frame the interviews. Verbatim interview transcripts were sent to each participant for review. During a scheduled follow-up interview, each participant had the opportunity to add, delete or change material. With the participants' permission, review interviews were also taped, with relevant comments made included in the analysis process.

Data Analysis

I began with a narrative analysis (Polkinghorne, 1995) to construct a chronological story (Stake, 1995) from the raw transcripts for each participant, guided by other studies of sojourners (Osland, 1995; Schild-Jones, 1999). The audit trail (Merriam, 1998) from the raw transcript to the stories is easily traceable. Each participant was offered the opportunity to review the constructed narrative and confirm that the distillation of her interview reflected her Nunavut sojourning experience. From the chronological narratives, I extracted major themes for each participant. I then used analysis of narratives (Polkinghorne, 1995) to identify commonalities amongst the individual themes. Learning how to learn culture emerged as a major theme for all participants. Individual variations on this theme illustrate sub-themes in the analysis. The resultant analysis reflects both the participants' shared experiences and each individual voice.

Findings

Participants agreed that sojourning had been a powerful learning experience. The analysis identified several different strategies for learning a new culture. These included being open; seeking cultural immersion opportunities; being mentored; experiencing meaningful moments; reflecting on experience; and academic researching.

\section{Keeping an Open Mind}

The one strategy that all the participants used was keeping an open mind, free from assumptions, both on first arriving in Nunavut and during their sojourns. Participants noted the need to have "the ability to recognize and recover from

50 Canadian and International Education Vol. 35 no. 1 - June 2006 
mistakes in a culturally appropriate way" (participant Deborah), to be open to people saying, "That's not okay, and that doesn't make sense for us" (participant Danya), and "to listen very, very carefully" (participant Fluff).

Immersion in Inuit Culture

Compared to their lives in southern Canada, all participants were immersed in a different cultural milieu and worked professionally with Inuit clients. But beyond that, they all sought involvement with Inuit culture outside of their professional responsibilities, through several different ways. Examples of involvement included:

Contact prior to professional involvement.

Both Bev and Meeka had extensive contact with Inuit culture before moving into a professional role. For Bev, what started as an effort to learn Inuktitut led to marriage with an Inuk. Meeka worked for many months at a day care with an Inuit woman and was a bus driver for Inuit kids for two years, her "favourite job ever". She reminisced fondly, "We just sang Inuktitut versions of 'You are my sunshine' and all the kind of good, fun stuff." Meeka also described the experience of dating an Inuk: "I...just participated in the community completely...like getting invited to little tents and making bannock and going for weekends with...local families."

Michelle wished that she had come to Nunavut in a non-professional capacity, as Meeka had. She remarked, "I really wish I would have been there ...being a janitor in the hospital, just to have a different experience of people, because there's...a wall when you are a mental health worker, and people relate to you differently."

\section{Social activities outside of professional roles}

For many of the participants socializing with Inuit involved spending time on the Land. As Michelle remembered, "Those were always beautiful experiences, being in a boat with some local people and watching wildlife and discovering seals and walruses or shooting at icebergs so we could have water for tea." Soshana also enjoyed her trips with Inuit out on the Land: "They'd take me out to their camps...I learned how to dry fish.... They taught me a lot of those really good basic skills.” Patricia described how she, too, sought contact with Inuit:

"One of the things I found really valuable... was to...be with them and do some of the things that I wouldn't ever have thought I would have done before I left: ...go in a komatiq [a large sled pulled by a dog team or ski-doo], go to the floe edge with my baby on my back."

Debbie doesn't like the cold, so she didn't go camping or do any of the traditional things the other participants did. Instead, her Inuit students were always welcome to come to her home and "drink endless cups of tea"; they visited, sewed parkas, and knitted.

Having children in the community. Deborah described how having a child immersed her in the life of the community. "Just because of the nature of the 
lifestyle and the community, my home...was always filled with hordes of thundering kids." Patricia, too, felt that having children really helped "because they love kids in Nunavut." She participated in family-related events, explaining, "I went to the feasts; I went to the graduations.....My kids went to the day care...”

Listening to Stories.

Meeka used to visit the local Elders' centre and listen to stories. She remembered, "It really showed me the historical differences, the cultural differences." Deborah also learned from Inuit friends "often just from saying 'Tell me a story'... which in Inuit culture is really appropriate”. Michelle, too, learned from listening to Inuit stories, recalling, "I just love hearing the stories of hunting.... One of the guys...would tell me that his favourite meal was to get a caribou and have some of its brain with Ritz crackers...It's a delicacy.”

Attending cultural events. Danya described going to Inuit cultural events: "I'd go to the dances...the food festivals. I tried seal.... lot of raw meats...the raw fishes...”

Trying to learn the language.

Most participants described trying to learn some Inuktitut. According to Deborah, "Even learning just the basics of the language is such an eye opener to how people think." She saw willingness to learn the language as an indicator of openness and effort. Meeka picked up enough Inuktitut so she could "talk to a four year old..." in the day care job. Later, she learned how to read Inuktitut phonetically and write it. Although she had no idea what she was reading, Meeka felt, "Even that built great rapport with the entire community."

\section{Being Mentored}

Developing a mentoring relationship with an Inuit colleague or friend or with a more experienced non-Inuit colleague or friend was featured in the narratives of many participants.

\section{Inuit mentors.}

Deborah explained how in every cross-cultural posting, she forms a really good relationship, often with an interpreter, and relies on that person to interpret much more than words. In Nunavut, Deborah described becoming very close friends with an Inuit government worker. Deborah recalled, "There were lots of taboos initially in the first year. There was stuff I just wouldn't get an answer to.not an appropriate question'....But as we got to know each other better, I...learned more." Similarly, Rebecca felt very fortunate to have the two women friends whom she could ask a lot of questions and who gave her the opportunity to express it if there was something she didn't understand. She commented, "Sometimes I got answers and sometimes I didn't." Patricia benefited when she gained a professional colleague who was Inuit and had about 17 years

52 Canadian and International Education Vol. 35 no. 1 - June 2006 
experience in social work. Patricia found her a real breath of fresh air and described it as "really helpful" to have someone she could bounce things off of professionally.

Although Fluff did not describe forming a specific mentoring relationship, she observed that her interchanges with Inuit colleagues and the Elders she worked with had a significant effect on her. Fluff remarked, "Sometimes I would become aware of how not only was the helping and the teaching...mutual but of how that all was changing me."

\section{Non-Inuit mentors.}

On arrival in Nunavut, Patricia felt "a natural gravitational pull towards other White people in the community" because she was a little uncomfortable and wasn't really sure what she was doing. Patricia had the feeling that other White people could teach her. What she found is: "Some of them can be really good teachers and others just want to impose their negativism." She was much more comfortable once she was able to pick and choose the people of the same race she wanted to spend time with. To check her impressions of the community, Patricia spoke a lot with another woman who had been in the North for fourteen years and seemed to have blended the South and the North really well. Patricia also went a lot to another non-Inuit woman who had been born and raised in Nunavut. Patricia would explain, "Okay this is what happened, and this, this, this....” The woman explained a lot of social behaviour to Patricia.

Like Patricia, Michelle had a mentor from her own culture in a senior mental health specialist, who was always supervising, always consulting. Without that support, Michelle said, "There's no way I could have been there and done what I did. It would have been impossible....We always had this ongoing fascinating conversation about what we were doing: the ethics, the dynamics, the culture." In every community that she visited, Soshana always had one person she could talk with and de-brief with about the personal and professional issues. "Sometimes it was a nurse at the nursing station, sometimes the wife of the Anglican minister."

\section{Moments of Meaning}

All the participants described critical incidents, when a specific situation gave them a deeper understanding of Inuit culture. For example, Michelle recounted a story that illustrates this kind of meaningful moment. While on a duty visit to a Nunavut community, she had been late for the hotel's communal dinner. An Inuk colleague told her, "They're serving raven tonight." Michelle, feeling surprised and naïve, said "You don't really eat raven do you?" He replied seriously, "We eat everything us Inuks....There's not a lot to eat on this land. Generally if it moves, I'll eat it." She responded politely, "Oh, well, it tastes not bad." Then, a little later, he said, "Have you seen the arctic frogs?” Michelle said, "You're kidding!" The man asserted, "Oh, no. We have fairly large frogs here and they have skin like a seal." Later, when Michelle told her supervisor about eating raven wings and seal skin frogs, she gently broke the news that 
Michelle had been duped by the kind of teasing typical of Inuit. Michelle commented about this incident, "I always had fun with that man....and I'm pretty sure I wasn't duped again.”

\section{Reflecting}

Several of the participants described using reflective strategies. Danya regularly called a close friend and fellow psychologist in the southern Canada to "debrief" her Nunavut experiences. Danya also remembered discussing Nunavut with other sojourners. Because many of the "Southerners" did not have a family up there, they would all get together and have conversations. "How do you make things different? How do you make changes? How do you help them make changes?” Fluff reported having a systematic process for reflecting on what she was learning. As she described it, "I'm not a counsellor for nothing. Talk, talk, talk, talk, talk....I'm a great journal writer and talker.” To help process her new experiences, Meeka also adopted some deliberate strategies:

I wrote a lot... and by asking a lot of questions, even really dumb ones, in safe environments, and then not accepting one answer. So...somebody nonInuit who'd been there for ten years, I'd ask them, sort of mull over that response, then ask...a born-and-raised Inuk...the same question and...seeing the two different answers and...comparing.

Meeka was clear that her reflection process was only partially successful. "Some stuff I just didn't understand. My then-boyfriend's mother who was Inuit, I didn't understand some of the laws that she would say: 'That's that family.' ... I didn't know how to process a lot of that stuff."

Rebecca's reflection on her experiences continued with a Northern Studies group that formed during her graduate program after leaving Nunavut. She commented, "I needed to talk about a lot of things....And your friends get bored and your family gets bored." Having a peer group really interested in the meaning of their Northern experiences was a great support.

\section{Researching}

Only a few participants referred to reading or studying about Inuit culture in any kind of formal academic way, despite the fact that all had university degrees. Rebecca had incorporated a northern theme into papers for her BSW program before moving north. Once in Nunavut, she continued the reading of Northern literature, including books of Inuit poetry and stories. After leaving Nunavut, Rebecca examined literature on the cultural effects of colonialism and northern social work practice, relating it to her personal experiences. Rebecca also made mental health issues in Nunavut the focus of her Master's thesis, spending two months in a different Nunavut community. Finding a lot more differences than she expected was a "rude awakening"

Deborah remarked that with every new international posting, she reads about the culture before going. So before moving to Nunavut, she remembered, "I just immersed myself and studied a lot." Some of her reading was particularly

54 Canadian and International Education Vol. 35 no. 1 - June 2006 
helpful in the child custody aspect of her job as a social worker by giving her an awareness of what to expect from kids and how kids relate to adults. She described how she applied information from a study out of McGill University on why Inuit children do badly in school on her arrival in Nunavut. "I was presented with child welfare investigation protocols that had me asking direct questions to a frightened child." She laughed as she remembered thinking, "Hello! I think this is set up for failure."

In contrast to Deborah and Rebecca, Soshana was emphatic about not reading anything about Inuit culture before she went. "It's all written by White people anyway." Instead, she based her work in Nunavut communities on this idea: "Given the appropriate knowledge, they can solve most of their own psychological problems and issues." Her initial approach was systematically to ask the different community groups what they felt the needs of their community were and what they wanted. As Soshana described this process, "They kept saying, 'You tell us'." Soshana would say, "You tell me. 'No, you tell us.' No, you tell me. And this went on for a year." Soshana eventually published her own scholarly article about this experience.

\section{Being Aware of Learning}

Several of the participants talked at some length about becoming aware of the changes in their thought processes, perception, and feelings as they occurred during their stay in Nunavut. But they also found it difficult to express the details of the changes. Their attempts to describe the learning process and the resultant changes gave the impression that what they were trying to talk about was a subtle and complex phenomenon, at best only partially visible.

\section{Linking language and thought}

For both Bev and Debbie, learning a new language led to major changes in their understandings of the other culture. In her interview, Bev observed that learning a language that is so different from English had done many things to her: "I'll never know them all." In a later e-mail, she expanded on how learning Inuktitut had affected her:

When I learned Inuktitut...the names for different kinds of snow, or the vocabulary around hunting and camping, I had a totally new view of the Land and of the relationship between man and nature that was only tangible when I was using Inuktitut to describe or to live in the Arctic environment. During the middle years of my stay in Nunavut, I remember the breakthrough that occurred when...I was finally able to conduct all of my parent interviews in Inuktitut. Suddenly my perception, and understanding of my students changed drastically: I had new empathy for their lives, was able to connect with them much more instantly, and was able to use vocabulary and experiential examples that made my teaching so much deeper and so much more effective....This was for me a very formative shift, which I believe I will never abandon....

Education canadienne et internationale Vol. 35 nº 1- Juin 200655 
Debbie described a similar experience of having “a revolution” in her mind when she learned to speak a little Cree, before going to Nunavut. She realized, "My thinking and the way I thought had nothing to do with the people I was involved with....They didn't think the same way I did....It didn't come as a gradual awareness....My brain literally changed." Debbie described this as going from the straight line to the circle. She commented, "We could spend years in a linear framework, but if the person that you're working with thinks in a circle, how are you going to work together?” What she ended up with was a circular-linear kind of framework where each contributed. When she came to Nunavut, Debbie explained, “It didn't take long for me to recognize that many of the people I was working with also thought in this circular way.” Debbie found it difficult to articulate an example of the difference in the linear and circular way of problem-solving. After a lengthy pause for thought, she said, "You're having problems, with your husband, so leave him! That's the obvious solution to people who think in a linear way. The consequences are quite clear. You leave him, then... at least you're not going to have that particular problem.” In contrast, she explained, "In a circular way...you come to understand that's only half of the issue, that it's not quite so clear cut. It isn't a matter of just simply...eliminating things; it's a matter of including things.” Debbie found most of the Inuit women who were in that situation had the view: "Yes, help me but that's not going to do any good if you only help me. You've got to help the other person, too.”

Debbie showed good metacognitive awareness of the changes in her thought processes, but she nevertheless commented when reviewing her own transcript, "Even after I read the interview, I thought this stuff is really hard to put into words. It's very intangible....I don't think you really do understand how much stuff you absorbed without knowing you've absorbed it.”

\section{Understanding non-verbal communicatio}

Meeka focussed on the changes in her awareness and understanding of nonverbal aspects of communication. Early in her sojourn, she described, "Making acquaintances....and asking questions and people just looking blankly at me.” And she would ask again...thinking, "Is there the language barrier here?...Can you hear me?” She explained, "I was oblivious to all the facial expressions, so they were definitely responding." When she figured that out, she felt like an "idiot”. Meeka compared herself to other non-Inuit, feeling that she had adopted some traits at a totally different level than a lot of the qablunaaq [Inuktitut word for non-Inuit]. Most White people picked up some facial expressions and some terminology, but these White people couldn't see the Inuit things she had picked up, because it wasn't the standard. Meeka's sense that changes had occurred was reinforced when she spent some time with newly arrived research scientists. "I could see how far I'd come.” Although Meeka was aware that internal changes had happened, she also found it difficult to express. As she mused about being 
involved with her Inuk boyfriend's family and community activities, "I think that provided something that I'm unaware of."

\section{Changing feelings}

Rebecca spoke of her awareness of how her feelings about her experiences changed during her time in Nunavut. "The beginning part was overwhelming. And then it was interesting to see how over time, that becomes normal." As illustration, she remembered hearing about a community feast and having visions of set tables and a variety of food. But when she went into the community gym, she explained, "It was a seal on a piece of cardboard, and that was the feast." She concluded laughingly, "You get into that within a couple of months, and then it just seems normal. That really did surprise me how quickly everything just kind of became mainstream.” Rebecca used the word "saturated" to describe the first months of her sojourn. "All of your senses are trying to absorb this new environment.” Throughout her time in Nunavut, Rebecca went through periods of feeling very enthusiastic and wanting to learn and through periods when she didn't. Then her enthusiasm would be renewed again. She commented, "I don't think you can maintain that enthusiasm all the time, so it's been an ebb and flow."

\section{Discussion}

Nonreflection and Reflection in Learning Culture

By moving to Nunavut to live and work, the participants' plunged themselves into disjuncture, thereby catalyzing the deep questioning that leads to learning (Jarvis, 1992). In describing themselves as "open", the participants showed the willingness to learn that Jarvis identifies as a necessary prerequisite for transformation. Further, they actively sought contact with Inuit culture outside their professional roles. By having social contact with Inuit and participating in the life of the Inuit communities, the participants intensified the level of disjuncture they encountered.

Significantly, the participants' response to disjuncture was learning rather than nonlearning. According to Jarvis (1992), non-learning is a common event in a familiar cultural milieu, as individuals often are too busy or too certain of their own correctness to take in new knowledge. In the unfamiliar context of Nunavut, the participants described relatively few instances of nonlearning. Debbie's dislike of cold resulting in nonparticipation in traditional Inuit activities, Rebecca's occasionally waning enthusiasm for learning, and Soshana's refusal to read academic research on Inuit culture are the few nonlearning examples that participants mentioned.

In their learning, the participants were largely self-directed. That is, they learned independently, without formal instruction (Jarvis, 1992). They showed metacognitive awareness of how to learn culture, articulating several different learning strategies that included staying open, seeking cultural immersion, being mentored by both Inuit and non-Inuit, reflecting, experiencing meaningful moments, and researching. These strategies, which are similar to 
those described in other narrative studies of sojourners (Osland, 1996; SchildJones, 1999; Taylor, 1994b), included both nonreflective and reflective learning (Jarvis, 1992), providing illustrations of the different types of learning Jarvis proposed in each of the two categories. The different learning strategies evident in this study are discussed below in terms of Jarvis' typology.

\section{Nonreflective Learning}

The participants' strategy of actively seeking immersion in Inuit culture outside their professional roles provided the opportunity for innumerable moments of preconscious learning, which Jarvis (1992) suggests is necessary for learning culture. Participants alluded to how their involvement in Inuit culture had changed them in ways they were not fully aware of, suggesting that much preconscious learning had indeed occurred. In their descriptions of listening to Inuit stories, or seeking cultural information from Inuit and non-Inuit mentors, these participants were learning from cultural authorities, a type of memorization. Such information is an important source of cultural learning for sojourners. In an interesting contrast, they did not rely much on learning from non-Inuit experts on Inuit culture. Participants experienced nonreflective skills learning when learning traditional skills through imitation and practice while camping with Inuit.

\section{Reflective Learning}

The participants' reflective activities such as journaling or discussions demonstrate their use of contemplation, a constant questioning of their experiences, in an effort to reach conclusions. The participants' narratives contained many descriptions of reflective skills learning when moments of meaning led to new responses and deeper understanding. For example, Michelle's story of the raven dinner and arctic frogs illustrates how she gained a sudden insight about Inuit humour and how to respond to such gentle teasing. Debbie's example of linear/circular thinking and how this applies in situations of spousal abuse is an example of experimental learning, the testing and modifying theory through practice.

\section{Gender Considerations}

Gender, a significant concern in development work (Rathgeber, 2005; Wood, 2005), needs to be addressed in the context of this study, because all the participants in this study were women. This fact raises the question of whether the ways of learning culture identified from their narratives are gender-specific. Lacking a comparable study of sojourning male counsellors, the answer must be speculative but can nevertheless be discussed in relation to evidence from other studies of sojourners.

Osland's (1996) study of male sojourners identified having a cultural mentoring relationship as an important element in the sojourning experience. Taylor's (1994b) study included participants of both genders, with four women

58 Canadian and International Education Vol. 35 no. 1 - June 2006 
and eight men. The primary learning strategies used by his participants included observing the other culture, participating in the other culture, and making friends with a member of the host culture, which are similar to the strategies of seeking cultural immersion and being mentored identified in the current study. Taylor did not analyze by gender, but the results are nevertheless suggestive that male sojourners use some of the same strategies to learn culture as female sojourners do.

A more detailed analysis might, however, might reveal gender differences in the specifics of implementing these common strategies, and in the cultural understanding gained in the process. In this study, some participants specifically referred to cultural immersion activities that they did primarily with women, such as sewing. Through sewing with Inuit women, a female sojourner might learn not only how to prepare hides or how to construct a parka from caribou skins but the social and spiritual meaning associated with clothing (Issenman, 1997). A male sojourner might have been more likely to spend time hunting with Inuit men, possibly learning how to divide and cache a carcass, and social and spiritual meaning associated with that activity (Wenzel, 1991). Further, the mentoring relationships these participants described having were all with other women, rather than being cross-gender. Thus, to the extent that Inuit culture is gendered, these participants might have acquired a preponderance of women's cultural knowledge.

The question of gender divisions within a culture is an important one to consider when assessing the extent to which gender affects the cultural learning experience. The Inuit women's association considered traditional Inuit culture to be egalitarian (Pauktutit, 1990). Inuktitut, the Inuit language, is not gendered in any respect, including personal names and pronouns (Gasser, 2003). In traditional Inuit culture, it was said a baby might change genders at birth. In Inuit naming practice, a child might be named for a person of the opposite sex and consequently might be raised in a cross-gender way (Ekho and Ottokie, 2001). Amongst contemporary Inuit, participation in education and employment does not indicate strong gender differences (Statistics Canada, 2001).

In cultures with more pronounced gender divisions, however, the content of the cultural knowledge acquired by a sojourner may show strong gender influences (Wood, 2005). Even if sojourning women and men use similar learning strategies, their cultural learning may be different because of gender differences embedded in the host culture. Acknowledging such gender differences, and the limitations of one's own cross-gender knowledge, is therefore another important element in development of the multi-cultural competence required to be an effective cross-cultural educator.

\section{Conclusion}

The participants in this study were able to articulate approaches to learning culture that they used during their sojourns that encompassed both nonreflective and reflective learning. Through nonreflective learning, they acquired an 
information base about Inuit culture. This nonreflective learning, however, did not include much typical academic learning, suggesting that this approach might be downplayed in programs aimed at developing cultural proficiency. Through reflective learning, they questioned their previous knowledge of their own culture, their recently acquired knowledge of Inuit culture, and the application of their professional skills, knowledge and practices in the new context. Both their nonreflective and reflective learning occurred in response to direct immersion in the new cultural context.

The participants' ability to articulate strategies used in their learning process suggests that learning to learn culture could be taught. Jarvis (1992) provided a theory of adult learning that recognizes the importance of both reflective and nonreflective learning. This distinction was useful for interpreting the findings from this narrative study, highlighting the importance of both types of learning when entering a new cultural milieu. Without the opportunity for nonreflective accumulation of a critical mass of cultural knowledge in at least two cultures and the subsequent reflection on that accumulated knowledge, it is unlikely a person could reach the advanced levels of ethnorelativism described by Bennett (1986) or transform into the intercultural person described by Kim (1988).

The synergy between the participants' learning strategies and the various components of Jarvis' theory points to the possibly use of his theory to guide development of formal educational efforts intended to enhance multicultural competence. A fruitful future research direction would be longitudinal studies of how sojourners learn culture, with an investigation of how the different types of learning interact and how sojourners make choices about which learning strategy to use for what kind of learning. For example, in listening to Inuit storytellers, the participants were probably engaging in both preconscious learning and memorization, while they may have used contemplation after hearing the stories to understand their meaning. A longitudinal study could provide more detail about this kind of interaction and about appropriate choice of learning strategies. In addition, future research should specifically explore gender issues, in terms of both learning strategies and cultural content. Such research would contribute to the development of more effective professional education for multicultural competence, based on a deeper understanding of how learning a new culture occurs.

\section{References}

Bennett, M.J. (2001). Developing intercultural competence for global leadership. In R. Reineke \& C. Fussinger (Eds.) Interkulturelles Management: KonzeptionBeratung-Training. Germany: Gabler.

Chang. W. (2004). A cross-cultural case study of a multinational training program in the United States and Taiwan. Adult Education Quarterly, 54, 174-192.

60 Canadian and International Education Vol. 35 no. 1 - June 2006 
Ekho, N. \& Ottokie, U. (2001). Interviewing Inuit Elders: Vol. 3 Childrearing practices. Iqaluit, NU: Nunavut Arctic College. Retrieved March 8, 2006 from http://www.nac.nu.ca/publication/vol3/index.html.

Engelbert, S. (2004). 'Intercultural training' in exchange situations for experts and management: a critical reflection. Intercultural Education, 15, 195-208.

Fuertes, J.N., Bartolomeo, M., \& Nichols, C.M. (2001). Future research directions in the study of counsellor multicultural competence. Journal of Multicultural Counselling and Development, 29, 3-12.

Gasser, M. (2003) How language works: The cognitive science of linguistics. Retrieved March 8, 2006 from http://www.indiana.edu/ hlw/index.html.

Issenman, B. (1997). Sinews of survival: the living legacy of Inuit clothing. Vancouver: UBC Press.

Jacobsen, W. (1996). Learning, culture, and learning culture. Adult Education Quarterly, 47, 15-28.

Jarvis, P. (1992). Paradoxes of learning. San Francisco: Jossey-Bass.

Kim, Y. Y. (1988). Communication and cross-cultural adaptation: An integrative theory. Philadelphia: Multilingual Matters.

Kim, Y.Y. (2005). Inquiry in intercultural and development communication. Journal of Communication, 55 (3), 554-577.

Kolb, D. A. (1984). Experiential learning. Englewood Cliffs, N. J.: Prentice-Hall.

Korhonen, M. (2002). Inuit clients and the effective helper: An investigation of culturally sensitive counselling. Unpublished doctoral dissertation, Durham University, England.

McAllister, G. \& Irvine, J.J. (2000). Cross cultural competency and multicultural teacher education. Review of Educational Research, 70, 3-24.

Merriam, S.B. (1998). Qualitative research and case study applications in education. San Francisco: Jossey-Bass.

Mezirow, J. (1978). Education for perspective transformation. New York: Center for Adult Education, Columbia University.

Mezirow, J. (1981). A critical theory of adult learning and education. Adult Education Quarterly, 32, 3-24.

Mezirow, J. (1991). Transformative dimensions of adult learning. San Francisco: JosseyBass.

Osland, J.S. (1995). The adventure of working abroad: Hero tales from the global frontier. San Francisco: Jossey-Bass.

Patton, M.Q. (1990). Qualitative evaluation and research methods (2nd ed.). Thousand Oaks, CA: Sage.

Polkinghorne, D.E. (1995). Narrative configuration in qualitative analysis. In J.A. Hatch \& R. Wisniewski (Eds.), Life history and narrative (pp. 5 -23). Washington, DC: Falmer Press.

Rathgeber, E. (2005). Gender and development as a fugitive concept. Canadian Journal of Development Studies, XXVI, 581-591.

Schild-Jones, L. (1999). The transcultural process: creative expression in a chaotic world. Unpublished doctoral dissertation, Fielding Institute, Santa Barbara, CA.

Schon, D. A. (1983). Educating the reflective practitioner: Toward a new design for teaching and learning in the professiosn. San Francisco: Jossey-Bass.

Stake, R.E. (1995). The art of case study research. Thousand Oaks, CA: Sage.

Statistics Canada (2001). 2001 Aboriginal population profile. Retrieved March 8, 2006 http://www12.statcan.ca/english/profil01ab/Details/details1inc.cfm?SEARCH=BEG

Education canadienne et internationale Vol. 35 nº 1- Juin 200661 
INS\&PSGC $=62 \&$ SGC $=6204003 \& A=\& L A N G=E \&$ Province $=62 \&$ PlaceName $=$ iqalu it\&CSDNAME=Iqaluit\&CMA=\&SEARCH=BEGINS\&DataType=1\&TypeNameE $=$ Town \&ID $=13587$.

Taylor, E. (1994a). A learning model for becoming interculturally competent. International Journal of Intercultural Relations. 18 (3), 389-408.

Taylor, E. (1994b). Intercultural competency: A transformative learning process. Adult Education Quarterly, 44 (3), 154-174.

Wenzel, G. (1991). Animal rights, human rights: Ecology, economy and ideology in the Canadian Arctic. Toronto, ON: University of Toronto Press.

Wihak, C. (2004). Counsellors' experience of cross-cultural sojourning. Unpublished doctoral dissertation, University of Alberta, Edmonton, AB.

Wihak, C. and Merali, F. (2005b). Multicultural counselling and spirituality: Counsellors' narratives from Nunavut. Canadian Journal of Counselling, 39, 245-259.

Wood, C. A. (2005). Different commonalities: Gender mainstreaming and the marginalization of difference in economic development. Canadian Journal of Development Studies, XXVI, 593-603.

Dr. Christine Wihak is an Assistant Professor in Workplace and Adult Learning, Faculty of Education, University of Calgary. Her research interests include the development of multicultural competence and anti-racist White Identity in helping professionals. Related to this interest, she conducts research on professional ethics in cross-cultural situations and on the relationship between cross-cultural sojourning and spirituality.

62 Canadian and International Education Vol. 35 no. 1 - June 2006 